\title{
Potter day raises charity cash
}

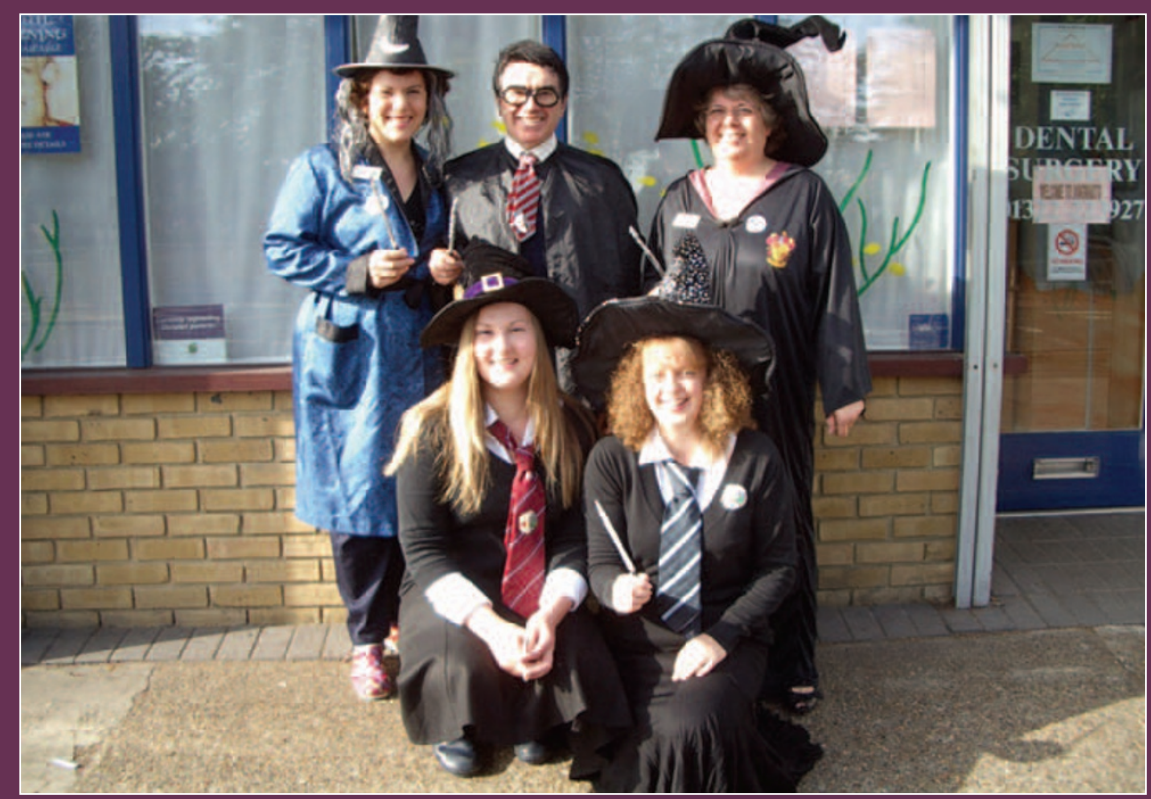

Staff at the Dartford Road Dental Centre took part in an annual 'Dress Up Day' on behalf of the dental charity Dentaid, raising funds for much needed dental and oral health care in the developing world.

The theme for the day was Harry Potter Hogwarts Magic. The idea came from dental nurse Beverley Bushell, who coordinated the make-up and costumes, and centre manager Kim Bennett, who tried to explain the purpose of the day to all the worried looking clients. The staff were all able to carry out their work and duties in full costume and make-up, much to the surprise of their clients, who were asked to make donations and buy raffle tickets. Wizards, wands and cloaks were the order of the day, along with Dr Donohoe's transformation into Harry Potter himself.

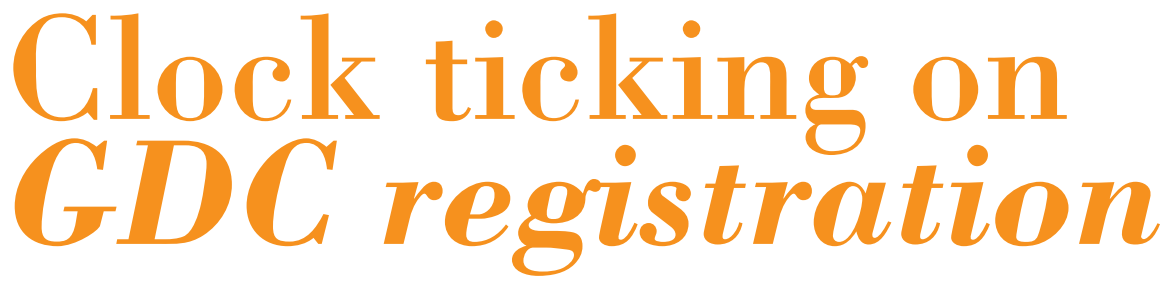

As the clock counts down to compulsory registration, the GDC is urging all dental technicians and dental nurses to register now to avoid missing the deadline of 30 July 2008.

'It may be one small step for you, but it is one giant leap for dental technicians and nurses as a whole. And a bigger one still for patient protection, says GDC president Hew Mathewson.

At the last count 6,797 dental care professionals (DCPs) from the four new groups had registered; 6,240 of whom are dental nurses; the rest dental technicians, clinical dental technicians and orthodontic therapists.

When registration becomes compulsory for all DCPs patients can feel confident that everyone who directly helps to deliver their dental care is properly trained and under a duty to maintain the high standards set by the GDC.

To register, you must demonstrate that you are qualified or experienced - or both, and that there are no health or character issues that would affect your fitness to work as a dental technician or dental nurse.

When you register, you make a commitment to behave ethically and professionally, and to meet and uphold the standards of the profession and commit to keeping your knowledge and skills up-to-date.

DCP titles, including 'dental technician' and 'dental nurse', will be protected by law, which means patients will be able to identify professionals who are qualified to use those titles, just as they currently can with dentists, dental hygienists and dental therapists.

Those who carry on working after 30 July 2008 without registering with the Council will fall foul of the law, the GDC warns.

By applying early dental nurses and dental technicians can have two years' registration for the price of one at the current price; after registering, no payment will be required until your first annual retention fee is due in July 2009.

Hazel Carpenter, who coordinates dental nurse training within NHS Lothian, was one of the first to join the new register. She says, 'It is certainly reassuring that dental nurses are now recognised, professional members of the dental team who will be able to contribute directly to improving oral health care.'

You can register now if you have an appropriate qualification. A list of the qualifications recognised for registration is available on the GDC website. If you have no formal qualification, you may be eligible to join on the basis of your experience.

You need a certain amount of the right experience, which is set out on the GDC's website. If you don't have enough experience now, you could make it up before the end of July 2008. When registration becomes compulsory you will need an approved qualification in order to register. So if you don't have the right qualifications during this socalled 'transition period', it is important to apply for registration as soon as possible.

Those who were on the Dental Technologists Association's or British Association of Dental Nurses' voluntary registers can apply for registration with the GDC on this basis.

To register as a clinical dental technician, dental technicians should have completed, and passed, a GDC-approved clinical dental technology course. Registration has been compulsory for more than a year, so if you haven't yet applied you can download an application pack from the GDC website, or get in touch with them and they will send you one in the post.

For more information or advice, check the GDC website at www.gdc-uk.org, email on GDCregistration@gdc-uk.org, or call 02078873800 . 